
World Ecology

\title{
Strategies to combat desertification for the twenty-first century in China
}

\section{Jingzhu Zhao , Gang Wu , Yingmin Zhao , Guofan Shao , Hongmei Kong \& Qi} Lu

To cite this article: Jingzhu Zhao , Gang Wu, Yingmin Zhao , Guofan Shao , Hongmei Kong \& Qi Lu (2002) Strategies to combat desertification for the twenty-first century in China, International Journal of Sustainable Development \& World Ecology, 9:3, 292-297, DOI: 10.1080/13504500209470124

To link to this article: http://dx.doi.org/10.1080/13504500209470124

Published online: 11 Oct 2010.

Submit your article to this journal $־$

Џll Article views: 101

View related articles $₫$

Citing articles: 9 View citing articles $\lessdot$ 


\title{
Strategies to combat desertification for the twenty-first century in China
}

\author{
Jingzhu Zhao', Gang Wu', Yingmin Zhao ${ }^{2}$, Guofan Shao ${ }^{3}$, Hongmei Kong ${ }^{d}$ and Qi Lu ${ }^{4}$ \\ 'Department of Systems Ecology, Research Centre for Eco-Environmental Sciences, Chinese \\ Academy of Sciences, Beijing, China \\ ${ }^{2}$ Chinese State Bureau of Environmental Protection, Beijing, China \\ ${ }^{3}$ Department of Forestry and Natural Resources, Purdue University, West Lafayette, USA \\ ${ }^{4}$ National Research Centre on Combating Desertification, Chinese Academy of Forestry, \\ Beijing, China
}

Key words: China, desertification, erosion, rangelands, aridity

\begin{abstract}
SUMMARY
During the past half century, China has experienced increasingly severe land degradation, soil erosion, and desert expansion. Desertification is affecting one third of China's total territory and the annual accelerating rate of desertification spread is as high as $2460 \mathrm{~km}^{2}$ in China. In 1996, China developed a National Action Programme to Combat Desertification (NAP), which is aimed to apply new legal measures and technical approaches to slow down desertification processes and achieve a long-term goal control desertification and alleviate poverty through continuous efforts to fight against desertification, stabilize mobile dunes, revegetate degraded rangeland and control soil erosion in arid, semi-arid, and dry sub-humid areas. The long-term and integrated strategies of China's NAP result in encouragement of social participation, legal institutional guarantees, policy making, and establishment of demonstrations/pilot projects to combat desertification at both national and provincial level.
\end{abstract}

\section{INTRODUCTION}

Desertification is increasingly threatening human lives in many regions of the world ( $\mathrm{Lu}$ et al., 2000). Since World War II, rapid growth in human population has led to over-grazing, excessive forest cutting, and blind agricultural production. As a result, agricultural lands have been degraded, soils deteriorated and eroded, and deserts have expanded. At present, $40 \%$ of the Earth's land area is desert or affected by desertification. Although more financial resources have been invested to combat desertification throughout the world every year, at least 10 million ha of land is turned into desertification-prone land or a desert-like landscape every year, causing damage of US $\$ 42$ billions per year (Zhao and $\mathrm{Li}, 2000$ ).

In China, the total area of desertificationaffected land covers $27.3 \%$ of the total territory. Desertification occurs in arid, semi-arid and dry sub-humid areas, covering 471 counties in 18 provinces and autonomous regions in the northeast, the central north, and the northwest China (Figure 1). By 1999, the desertificationaffected area in China had exceeded 2.6 million

Correspondence: G. Wu, Department of Systems Ecology, Research Centre for Eco-Environmental Sciences, Chinese Academy of Sciences, Beijing, 100085, China. e-mail: wug@mail.rcees.ac.cn 


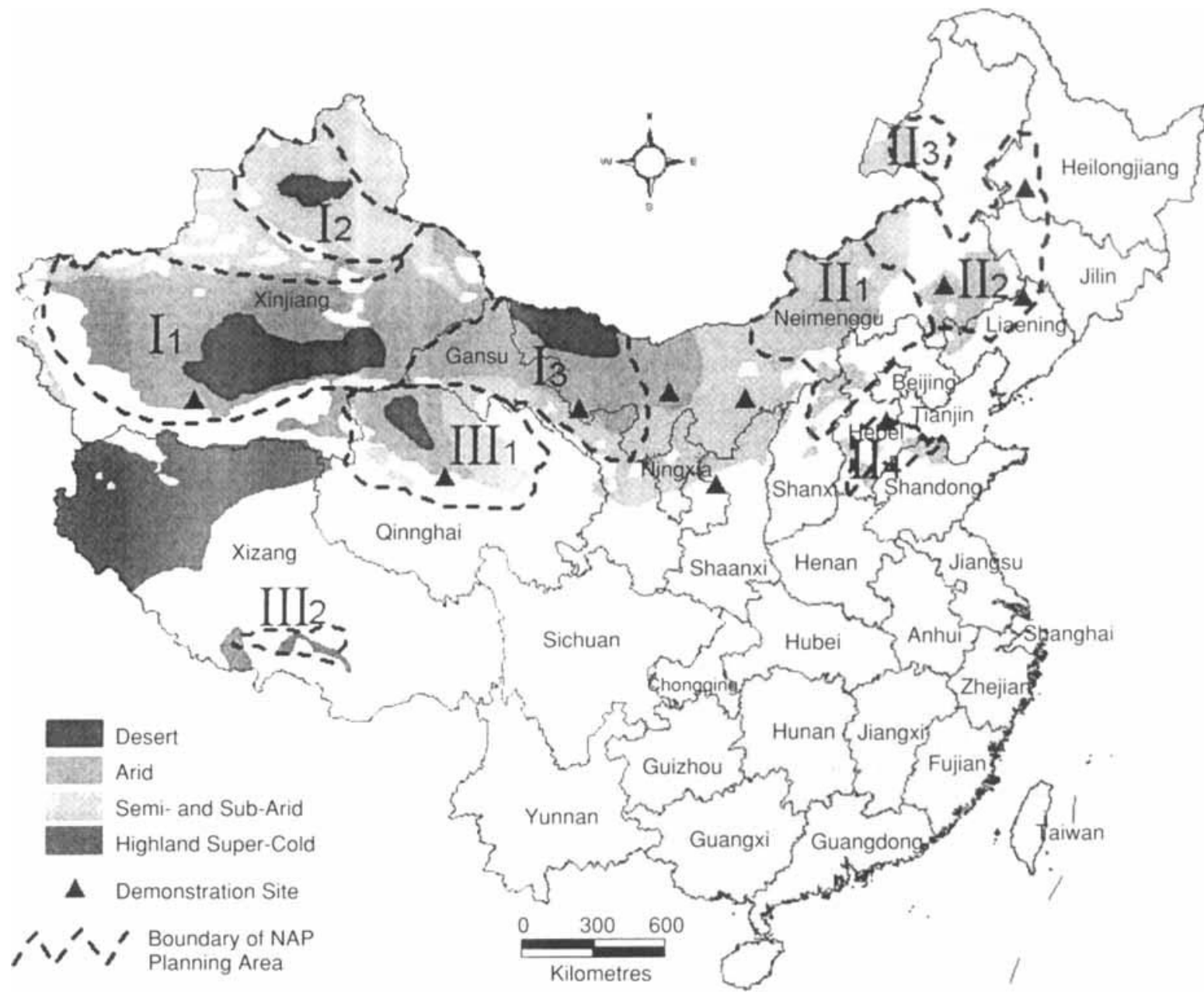

Figure 1 Locations of demonstration sites and classification of NAP Project area. Ten demonstration sites were selected to deal with the issue of severely affected lands, economically disadvantaged and potentially changeable areas. There are four sites in arid area: Hetian at the southern edge of Taklimakan Sand Desert, Wuwei of Gansu Province, Dengkou of Inner Mongolia, and Guinan in Qaidamu Basin of Qinghai Province; two sites in the semi-arid area: Mu Us Sandy Land and Ih Ju Prefecture; four sites in semi-arid and dry sub-humid area: Chifeng of Inner Mongolia, Nenjiang Sandy land of Heilongjiang Province, Zhangwu of Liaoning Province, and the middle and lower reach of Yongding River in Beijing. The arid area is divided into three subareas: $I_{1}=$ Protection and rehabilitation engineering at the periphery of Taklimakan Sand Desert; $\mathbf{I}_{2}=$ Rehabilitation engineering of vegetation protection in Guerban Tonggute Desert; and $\mathbf{I}_{3}=$ Rehabilitation engineering at the periphery of Badain Jilin Sand Desert, Tengger Sand Desert, and Ulan Buh Deserts. The semi-arid and dry sub-humid area is divided into four sub-areas: II $_{1}=$ Comprehensive rehabilitation engineering of sand land around Beijing; $\mathrm{II}_{2}=$ Revegetation engineering in Kurqin Sandy land; $\mathrm{II}_{3}=$ Vegetation restoration and rehabilitation engineering in Hulun Bur Sandy Land; and $\mathrm{II}_{4}=$ Comprehensive rehabilitation engineering of sandy lands along the ancient river courses of the Yellow River. The sub-areas of cold desert in uplands include III $_{1}=$ Comprehensive rehabilitation engineering of sandy lands in Qaidam Basin; and $\mathrm{III}_{4,}=$ Comprehensive rehabilitation engineering along the headwater river valleys on the Tibet-Qinghai Plateau (Zhao, 1997)

$\mathrm{km}^{2}$, of which, $61.3 \%$ was caused by wind erosion, $7.8 \%$ by water erosion, $13.8 \%$ by freezing and melting processes on cold plateaus, $8.9 \%$ by salinization and alkalization, and $8.2 \%$ by other factors. The annual accelerating rate of desertification averages $2460 \mathrm{~km}^{2}$ (Figure 2), and the status and trend of desertification process in China are overwhelming (CNC, 1996).

In 1994, China signed the International Convention to Combat Desertification, drafted by the international community ( $\mathrm{Wu}$ and Cai, 1998). Since then, China has invested a large 


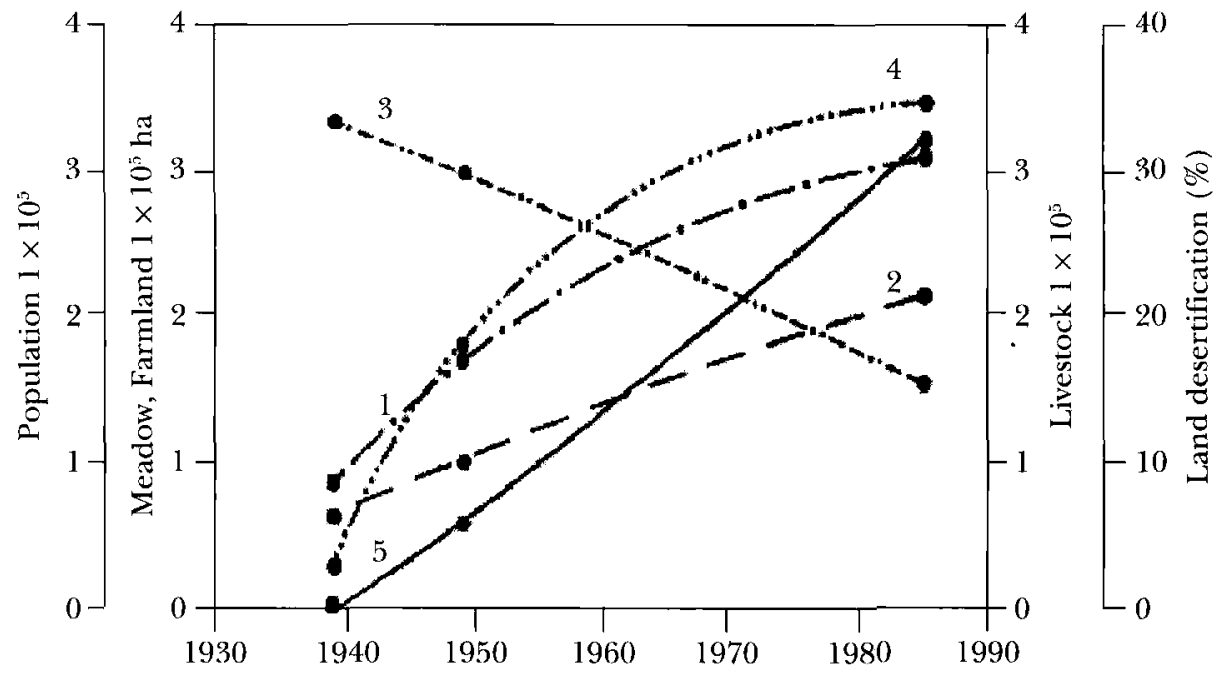

Figure 2 Changes in population, livestock and desertification in the Shangdu County of Inner Mongolia, China. 1, Population change; 2, Farmland change; 3, Meadow change; 4, Livestock quantity change; 5, Desertification change

proportion of net income in solving ecological and environmental problems. In the late 1990s, China developed a series of environmental and ecological programmes, including the Natural Forest Protection Programme (NFPP) (Zhang et $a l ., 2000)$, which focuses on forest ecosystem protection and restoration along major river systems, and the National Action Programme to Combat Desertification (NAP), which is aimed to apply new measures to control land degradation, combat desertification and minimize the expansion of shifting sands, and to attract a long-term goal - immigrant population when dune movement has retreated and shifting sands are stabilized in arid, semi-arid, and dry subhumid areas (SFD, 2000).

\section{WHAT HAPPENED IN CHINA?}

The causes of desertification in China are the resultant actions of climate and human factors but driving factors are the rapid growth of human population and irrational land-use practices, including ecosystem destruction, over-grazing, deforestation, and crop cultivation on steppe, desert steppe and rangelands. China has a long agricultural history, but desertification has become a notable phenomenon since 1950 . For example, sand-dust storms have occurred once every 30 years from $300 \mathrm{BC}$ to 1950 , once every two years during the period from the 1960s to the $1980 \mathrm{~s}$, but once every year in the 1990s. In 2000 alone, sand-dust storms occurred 11 times (Wu et al., 2000).

In the period between 1950 and 2000, China's development has experienced four phases:

(1) Quick development (1950-1966). China formulated political, economic, and social laws, but few concerns were paid to environment protection and ecology restoration. The modern policy on population then was that more human population meant more manpower for overcoming difficulties while changing the environment. Human population was rapidly increased, but natural resources sharply declined at the same time.

(2) Food production (1967-1980). The quantity of food became a major concern for rapid growth of the human population. State policies encouraged the expansion of croplands by deforestation, opening of grasslands and wetlands in order to feed more population. Natural resources were further mis-managed by the blind exploitation in 1960s.

(3) Economic construction (1981-1990). China laid her focus mainly on social reforms and economic development. Both of them have achieved their goals with great success. However, natural resources were 
consumed at an even higher level. As a consequence, large-scale soil erosion, environmental pollution, sand-dust storms and disastrous floods have become more frequent. To control these problems in Northern China, the 'Three-North Regions' Shelterbelts Development Project was initiated, with a huge financial input from the central government and local authorities.

(4) Dealing with natural disasters (1991-2000). China's economy has grown with continuous development. However, natural disasters, including sand-dust storms and catastrophic floods threatened sustainable economic development. With more capital available from a booming economy, China has developed a series of national or regional level programmes to fight against natural disasters nationwide ( $\mathrm{Li}, 1997)$.

\section{DESERTIFICATION AFFECTED AREAS}

\section{Oasis and fringe areas of desert in the arid zone}

These types of affected areas are located in Xinjiang, Inner Mongolia, and Gansu Provinces, containing 94 counties. Project focus is laid on desertification prevention at the fringe of the Taklimakan Sand Desert, vegetation protection in the Guerban Tonggut Desert, and fixation of sand dunes and stabilization of shifting sand around the Baidan Jilin and Tengger Sand Deserts (Figure 1).

\section{Sandy land in semi-arid and dry sub-humid areas}

These types of sandy land are distributed mainly in 215 counties of 10 provinces and autonomous regions, such as Inner Mongolia, Shanxi, Beijing, Tianjin, Hebei, Heilongjiang, Jilin, Liaoning, Shandong and Henan. Project areas include the integrated rehabilitation of sandy land areas adjacent to Beijing, revegetation of degraded rangeland in Horqin Sandy Land, vegetation rehabilitation in Hulun Bir Sandy Land, and the comprehensive improvement of deteriorated soil along the ancient river course of the Yellow River (Figure 1).

\section{Cold deserts on upland and plateaus}

This type of desert-like landscape is distributed in 30 counties of Qinghai Province and the Tibet Autonomous Region. Project areas include the integrated management of desertification-prone land in the Qaidam Basin and the comprehensive improvement of sandy land along the middle reaches of the Yaluzangbu River (Figure 1) (CNC, 1996).

\section{GOALS AND STRATEGIES}

In 1996, the central government approved and provided financial support to the NAP. It is aimed to protect the living environments of large and middle-sized cities; and to improve the ecology of the affected ecosystems; to ensure food security; to ameliorate croplands; to restore natural vegetation in ecologically fragile areas where desertification spreads; to promote soil and water conservation; to rehabilitate desert fringe areas and degraded oases where human development previously prevailed; to protect the existing natural vegetation from desertification; and to strengthen the multiple-use policy in arid and semi-arid areas (Jiang, 2000).

The implementation of NAP involves 12 provinces and autonomous regions, including Shaanxi, Gansu, Ningxia Qinghai, Xinjiang, Inner Mongolia, Tibet, Shanxi, Hebei, Liaoning, Jilin, and Heilongjiang. The priority areas of the NAP are the Loess Plateau, forest-grassland ecotones, grassland-desert ecotones, limestone areas, and uplands with thin soils in Guangxi, Guizhou, Sichuan, Chongqing, Inner Mongolia, Tibet, and Hebei (Figure 1) (Li, 1997). These provinces and autonomous regions were financed by both the central government and local governments, whereas the rest of the NAP was funded by local authorities. The implementation of the NAP is programmed to be conducted in three phases:

Phase One (1996-2000). During this phase, the main focuses were on survey, investigation, inventory, training and capacity building. Ten demonstration sites were selected for the 
application of different approaches for combating desertification (Figure 1). In response to different tasks, three national centres were stationed at different institutions, such as the National Research and Development Centre for Combating Desertification at the Chinese Academy of Forestry (RDCCD), the National Centre for Desertification Monitoring (NCDM), and the National Training Centre for Combating Desertification (NTCCD). A handbook, entitled Methods of Desertification Combating in China, is under revision. The goals of the projects are to slow down the acceleration of the desertification process and to restore the degraded ecosystems in selected regions.

Phase Two (2001-2010). The targets are the priority areas of the NAP. The NAP area is divided into nine sub-areas (Figure 1), and its goal is to rehabilitate 6 million ha of wind-eroded lands, to reforest 4.8 million ha of water-eroded lands, to revegetate 17.5 million ha of degraded steppe, desert steppe and rangelands, to reclaim 5 million ha of salinized/alkalized lands, and to establish 165 natural reserves and conservation areas covering an area of 65.7 million ha in arid, semiarid and dry sub-humid areas.

Phase Three (2011-2050). The goal is to rehabilitate the majority of the entire desertification affected lands in 12 provinces and autonomous regions. The total area of natural reserves will be as high as 91.35 million ha. Ecosystems in the affected areas will be restored and economic development will be promoted in a sustainable way (Zhao et al., 1996).

The strategies of the NAP are focused on control of land degradation, fixation of sand dunes, stabilization of shifting sands and control of soil erosion, blind crop cultivation and extensive dry farming in the slope loess area of Western China; on protection of the existing forests and grasses and restoration of native vegetation that have been subject to human activities in central and western China; on control of plunder-like grazing in typical steppe zones in the northwest China; on preservation and revegetation of the transitional zone of desert and desert steppe; on increase of vegetation coverage in heavily grazed arid and semi-arid areas; on establishment of wetland reserves where both native herb varieties and wild animal species survive; on plantation of shelterbelts networks in sandy land areas composed of arbor tree, brush, and grasses; and on revegetation of natural vegetation on slopes terraces $>25^{\circ}$.

\section{IMPLEMENTING APPROACHES}

The NAP calls for social participation in the efforts to combat desertification, encourages local people to share the responsibility for implementing the National Social and Economic Development Plan in the twenty-first century through the development and implementation of long-term plans to combat desertification, the optimum management of mid-term plans to combat desertification, and the adoption of advanced research achievements and technology, know-how and practice. International exchanges and cooperation at both bilateral and multilateral levels are actively encouraged. Air-seeding is one of the practical techniques applied in selected areas (Zhu, 1996) and technical transfer of this technique is possible for both domestic production units and project administrations abroad.

The central government has facilitated a Steering Committee for Combating Desertification composed of 17 state missions and ministries, including the State Forestry Administration, the Ministry of Foreign affairs, the State Planning and Development Commission, the Ministry of Finance, the State Commission of Trade, the Ministry of Science and Technology, the Ministry of National Territory and Natural Resources, the Ministry of Agriculture, the Ministry of Water Resources, the Ministry of Railways, the Ministry of Transportation, the State Environmental Protection Administration, the Chinese Academy of Sciences, the People's Bank of China, the State Tax Supervision Administration, the State Poverty Alleviation Bureau, and the State Integrated Agriculture Development Bureau. The task of the committee is to coordinate all the governmental efforts and development initiatives as regards the combating of desertification and international cooperation in this field, including the implementation of UNCCD and NAP at national level. A coherent organization system is being gradually developed from central to local governments for sound implementations of NAP. 
Through demonstration sites and pilot projects, some significant progress has been achieved in the field to combat desertification and to control land degradation. For example, a series of new plant species were selected, more effective regeneration techniques were developed, indicators for monitoring and evaluation systems were established, space-based technology and remote sensing techniques were widely applied as early warning systems to predict the occurrence and spread of desertification. These initial achievements helped convince the central government of the value of the Western China Development Initiatives in 1999. The NAP is the essential part of the environment protection and ecology restoration which lays the foundation for the Western China Development Initiatives (Zhao et al., 2000). In turn, the implementation of the Western China Development Initiatives guarantees the implementation of NAP at a national level and the LADPs (Integrated Local Area Development Programmes) at local level.

China has gained a great deal of experience and developed suitable techniques for combating desertification which are available for dealing with the same issues in other parts of the world. Entrusted by UN organisations and host country governments, China has sponsored expert missions to African countries to help them fight against desertification (Wang et al., 1999). Not only the Chinese government and people profit from the implementation of NAP, hut also regional and global efforts will be focused on the control of the issue of desertification, through bilateral and multilateral cooperation in research and training aspects between the countries of the party of the UNCCD

\section{AGKNOWLEDGEMENTS}

The authors thank Prof. Wenhua Li, Academician of the Chinese Academy of Engineering for his supervision, and the staff members of RDCCD, NCDM, and NTCCD for their useful information. This study was supported by the National Natural Science Foundation of China (No. 79930800).

\section{REFERENCES}

China National Committee for the Implementation of the UN Convention to Combat Desertification (1996). Country Report on Combating Desertification. The Proceedings of The Asia-Africa Forum on Combating Desertification, Beijing, pp. 12-14

Jiang, Z. (2000). Fifty years of Prospering Forestry with Science and Technology to Green for a Brilliant China. Review of China Agricultural Science and Technology, 2(5), 10-15 (In Chinese)

Li, X. (1997). UNDP Capacity Building Project on Combating Desertification - CPR/96/111. Secretariat of China National Committee for the Implementation of the UN Convention to Combat Desertification, Beijing, p. 6. (In Chinese)

Lu, Q., Yang, Y. and Wu, B. (2000). Strategy for Scientific Research and Integrated Rehabilitation of Desertification in 21 st Century. Review of China Agricultural Science and Technology, 2(1), 47-53 (In Chinese)

State Forestry Administration (2000). Project Programming for the Prevention and Cure of Desertification in Major Areas. Revised Draft National Action programme to Comhat Desertification, Beijing (In Chinese)

Wang, T., Zhao, H. and Xiao, H. (1999). Journal of Desert Research, 19(4), 299. (In Chinese)
Wu, G., Li, J. and Zhao, J. (2000). Fundamental Ecological Environmental Problems and Its Countermeasures in Northwestern China. China Soft Science, 118(10), 12-17 (In Chinese)

$\mathrm{Wu}, \mathrm{G}$. and Cai, Q. (1998). Expression as a whole of research content of the watershed. Acta Ecologica Sinica, 18(6), 9-15 (In Chinese)

Zhang, P., Shao, G., Zhao, G., Le Master, D.C., Parker, G.R., Dunning, J.B., Jr. and Li, Q. (2000). China's Forest Policy for the 21st century. Science, 288, 2135-6

Zhao, M. (1997). UNDP Capacity Building Project on Combating Desertification-CPR/96/111. Secretariat of China National Committee for the Implementation of the UN Convention to Combat Desertification, Beijing, p. 1. (In Chinese)

Zhao, J., Xiao, H. and Wu, G. (2000). Comparison analysis on physical and value assessment methods for ecosystems services. Chinese Joumal of Applied Ecology, 11(2), 290-2

Zhu, G. (1996) . Desertification Combating in China. The Proceedings of the Asia-A frica Forum on Combating Desertification, Beijing, p. 5 